\title{
Dislocation Activity, Stable Crack Motion and the Warm-Prestressing Effect in Magnesium Oxide.
}

\author{
Andrew S. Booth and Steven G. Roberts*
}

\author{
Department of Materials, University of Oxford
}

\section{Oxford, OX1 3PH, England}

\begin{abstract}
Four-point bend tests were performed on precracked single crystal $\mathrm{MgO}$ specimens at different temperatures and strain rates. A large amount of stable crack growth before fracture occurred; etching revealed dislocations in the crack advance region. We believe that dislocation sources near to the crack tip emit loops, producing shielding and antishielding dislocations; the latter promote crack advance by a repeated microcleavage mechanism. "Warm-prestressing" experiments, which improve the room temperature fracture toughness by dislocation shielding, were performed. There was a prestress below which no "warm-prestressing effect" (WPSE) was exhibited and the magnitude of the WPSE increased with increasing prestressing temperature.
\end{abstract}

[Keywords: Fracture, Dislocations, MgO, Brittle-Ductile Transition.]

\section{INTRODUCTION}

One of the most important factors that affects the fracture stress and ductility of a material is crack tip shielding by dislocations emitted from the crack tip or already present in the material ${ }^{1-4}$. This has the effect of lowering the local stress intensity at the crack tip, compared to the externally applied stress intensity, so increasing the applied stress at fracture.

\footnotetext{
* Supported by the Science and Engineering Research Council (Advanced Research Fellowship).
} 
Dislocations near to a crack tip will interact elastically with the crack and hence modify the stress intensity at the crack tip $\left(\mathrm{K}_{\mathrm{eff}}\right)$;

$$
\mathrm{K}_{\mathrm{eff}}=\mathrm{K}-\Sigma \mathrm{K}_{\mathrm{d}}
$$

where $\mathrm{K}$ is the applied stress intensity factor and $\mathrm{K}_{\mathrm{d}}$ is the stress intensity factor due to each dislocation. $\mathrm{K}_{\mathrm{d}}$ varies inversely as the square root of the distance between the crack tip and each dislocation. Thus the local stress intensity may be reduced by the presence of dislocations; this decrease in $\mathrm{K}_{\mathrm{eff}}$ is termed dislocation "shielding" of the crack tip from K. Dislocations emitted from the crack tip always have a Burgers vector of the sign that will reduce $\mathrm{K}_{\mathrm{eff}}$. Dislocations not generated from the crack tip may decrease or increase the local stress intensity, depending on the sign of their Burgers vector. This latter case is termed "antishielding" and such dislocations will be attracted towards the crack tip.

The dynamic crack tip shielding model of Hirsch, Roberts and Samuels ${ }^{3}$ (HRS) considers the shielding of the crack tip from dislocations emitted from sources both at and near the crack tip. The model predicts that where dislocation sources are not present at or near the crack tip at the onset of loading, the brittle to ductile transition (BDT) should be sharp, with a rise in stress intensity at fracture $\left(\mathrm{K}_{\mathrm{F}}\right)$ over a very narrow temperature range. Conversely, the model predicts that where dislocation sources exist at the crack tip before any load is applied, the transition should be smooth, with a gradual rise to fracture over a wide temperature range. Warren ${ }^{4}$ performed experiments on single crystal silicon, using pre-deformation to introduce dislocation sources in a controlled manner, and confirmed these predictions.

Another effect of the pre-existing dislocation arrangement on the BDT is found in the "warmprestressing effect" (WPSE) experiments performed on single crystal silicon by Samuels and Roberts ${ }^{5}$ and Booth, Cosgrave and Roberts ${ }^{6}$. Here, silicon specimens are deformed at a temperature above the brittle-toductile transition temperature (BDTT), to a stress level that is above that for fracture at temperatures below the BDTT but below the yield stress of the specimen at the temperature of deformation. The specimen is then unloaded, cooled to room temperature and reloaded. It is found that the fracture stress intensity $\left(\mathrm{K}_{\mathrm{F}}\right)$ at room temperature is similar to that to which the specimen had been loaded at the higher temperature, i.e. above the normal $\mathrm{K}_{1 \mathrm{c}}$. Dislocations that had been generated on loading are "frozen in" on unloading and cooling to room temperature, then shield the crack by $\Sigma \mathrm{K}_{\mathrm{d}}$. This reduces the local stress intensity at the crack, so that on reloading, $\mathrm{K}_{\mathrm{F}}$ is greater than the normal room temperature value. 
In molybdenum ${ }^{7}$, where cracks cannot be introduced without the production of dislocations near to the crack tip, the brittle to ductile transition is smooth. $\mathrm{K}_{\mathrm{F}}$ rises steadily with increasing testing temperature in the range $77-250 \mathrm{~K}$. This is unlike silicon ${ }^{5}$ or sapphire ${ }^{8}$, where crack tips can be produced that are essentially dislocation-free, and where the only available dislocation sources are at the specimen surface. The HRS model ${ }^{3}$ is able to make good predictions of the BDT behaviour of molybdenum, assuming that shielding dislocations are emitted from the pre-existing crack tip sources.

Unlike sapphire or silicon, molybdenum exhibits stable crack growth (SCG) before final fracture. Examination of fracture surfaces shows that the shallow "thumbnail" precracks (introduced by spark discharge) extend by up to $20 \%$ before final fast fracture ${ }^{7}$. The region of crack extension appears smooth, except at the highest temperatures, where fine scale crystallographically-oriented microcleavage steps are observed, similar to those seen in iron-silicon alloys by Lii, Chen, Katz and Gerberich ${ }^{9}$. Etching shows that the region of crack extension contains a very high density of dislocations. It was thought that the mechanism of stable crack growth might be microcleavage promoted by antishielding dislocations emitted from the crack tip sources (as first proposed for $\mathrm{SCG}$ in $\mathrm{NaCl}$ by Weiderhorn, Moses and Bean ${ }^{10}$ ). It was not possible in molybdenum to determine experimentally the mechanisms of the stable crack advance because of the very fine scale of the processes.

We describe here experiments on magnesium oxide $(\mathrm{MgO})$. Cracks in this material were found to grow stably during stressing, before final fast fracture; like cracks in molybdenum, the mechanism appears to be one of dislocation-induced microcleavage. However, in $\mathrm{MgO}$, the dislocations are confined to a small number of slip planes, with no large scale cross-slip. The experiments were carried out above room temperature (unlike molybdenum) so that "frozen-in" dislocation structures, representative of those operative during crack advance, could be seen by etching of fracture surfaces at room temperature. Results from these experiments indicate the probable nature of the dislocation processes causing stable crack advance in semi-brittle crystals. Warm-prestressing experiments were also performed, and showed that $\mathrm{K}_{\mathrm{F}}$ in $\mathrm{MgO}$ can be enhanced by a hightemperature stress cycle. 
In this paper, the term "brittle-ductile transition" is used to refer to the fracture behaviour in the temperature range within which fracture occurs at a stress intensity $\mathrm{K}_{\mathrm{F}}{ }^{*}$ which is higher than the "lower shelf" stress intensity for fracture, $\mathrm{K}_{1 \mathrm{c}}$.

\section{EXPERIMENTAL PROCEDURE}

Four-point bend specimens were produced from a rectangular block of single-crystal magnesium oxide of purity $99.97 \%$ supplied by Koch Chemicals Ltd (UK). Figure 1a shows the crystallographic orientation and dimensions of the specimens. Figure $1 b$ shows the orientation of the $\{110\}$ slip planes within the specimens. Specimens were oriented by X-ray Laue methods and cut using a Capco Q35 diamond saw. Initial grinding, to produce flat specimens, was performed using a Logitech PM2a polishing machine with a slurry of $9 \mu \mathrm{m}$ diameter alumina powder in water on a glass wheel. One side, to be used as the tensile face in experiments, was further ground with finer alumina particles $(3 \mu \mathrm{m}$ and $1 \mu \mathrm{m})$ and then polished on a hard cloth surface impregnated with a $6 \mu \mathrm{m}$ diamond grit and lubricated with an oil-based solution. The final polishing was performed using a chemical polish of orthophosphoric acid at a temperature of $300^{\circ} \mathrm{C}$. This technique removes all traces of polish lines from the mechanically polished surfaces; the "tensile" surface is easily distinguished under the optical microscope because of its superior finish. Precracks were introduced by drawing a $90^{\circ}$ diamond scriber across the middle of this surface, parallel to the (001) end face. A balanced-arm apparatus was used, so that a controlled load and scribing speed could be applied to produce reproducible precracks. Varying the load applied on the diamond scriber varied the depth of the induced precrack; an applied load of $102 \mathrm{~g}$ produced a precrack depth of $55 \mu \mathrm{m}$, one of $182 \mathrm{~g}$ produced a precrack depth of $85 \mu \mathrm{m}$. These were the two crack depths used in the fracture experiments.

Four-point bend testing was performed using an Instron 1121 testing machine. The loading apparatus used in the experiments was made from stainless steel with the contact edges made from cylindrical rods of electropolished molybdenum of $1.5 \mathrm{~mm}$ diameter. This testing apparatus is similar to that used in previous

\footnotetext{
${ }^{*}$ Note that we use $\mathrm{K}_{1 \mathrm{c}}$ to denote the stress intensity at the crack tip for fracture (a material parameter), and $\mathrm{K}_{\mathrm{F}}$ to denote the applied stress intensity at fracture in a given experiment; this may be greater than $\mathrm{K}_{1 \mathrm{c}}$ because of dislocation shielding.
} 
experiments on silicon ${ }^{4-6}$ and is shown in figure 2. For testing at elevated temperatures, the specimen was heated in air by a cylindrical wire-wound resistance furnace placed around the glass tube.

The initial series of experiments were simple fracture tests in order to establish whether, and at what temperature $\left(\mathrm{T}_{\mathrm{c}}\right)$, a brittle-ductile transition occurred. Tests were originally performed with a cross-head speed, $\underline{\delta}$, of $8.3 \times 10^{-5} \mathrm{~mm} \cdot \mathrm{sec}^{-1}$, which corresponds to an outer fibre strain rate, $\underline{\varepsilon}$, of $5.9 \times 10^{-6} \mathrm{sec}^{-1}$, using the relation:

$$
\varepsilon=\frac{6 h \delta}{3 l(L-l)+(L-l)^{2}+4 h^{2}}
$$

where $L$ and $l$ are the outer and inner roller spacings and $h$ is the specimen depth. The outer fibre stress at an applied load $P$ is given by :

$$
\sigma=\frac{3 P(L-l)}{2 w h^{2}}
$$

where $w$ is the specimen width. For a crack of depth $a$ traversing the tensile surface of a specimen, the stress intensity $K$ is given ${ }^{11}$ by:

$$
\text { where } \quad \alpha=1.12-1.39 \frac{\frac{a}{h}+7.32 \frac{a^{2}}{h^{2}}-13.1 \frac{a^{3}}{h^{3}}+14 \frac{a^{4}}{h^{4}}}{}
$$

Initially a precrack depth of $55 \mu \mathrm{m}$ was used. The stress intensity loading rate was subsequently increased by increasing the depth of the precrack to $85 \mu \mathrm{m}$ and by increasing the strain rate to $5.9 \times 10^{-5} \mathrm{sec}^{-1}(\underline{\delta}=$ $\left.8.3 \times 10^{-4} \mathrm{~mm} \cdot \mathrm{sec}^{-1}\right)$. The variation of $\alpha$ with crack depth for the crack depths used in these experiments is not great: for a $1 \mathrm{~mm}$ thick specimen with a precrack depth of $55 \mu \mathrm{m}, \alpha=1.06$, and with a precrack depth of $85 \mu \mathrm{m}$, $\alpha=1.05$. There is a minimum in $\alpha$ of 1.04 at $\mathrm{a}=160 \mu \mathrm{m}$, beyond which $\alpha$ rises to 1.08 at $\mathrm{a}=250 \mu \mathrm{m}$. All values of $\sigma$ and $\mathrm{K}$ reported here were derived from the applied load, the measured specimen dimensions and the actual crack depth, measured after fracture.

The load / displacement curves for all tests were found to show a region of strongly increasing slope during the initial stages; we attribute this to "settling" of the apparatus, probably combined with some plastic deformation of the specimen immediately under the rollers (etched tensile and compressive surfaces always showed a very high dislocation density in these regions). Beyond this initial stage, curves for all specimens showed slightly increasing slope, probably because of increasing plastic flow under the rollers. 
Two sets of warm-prestressing experiments were performed. In the first set of experiments, the temperature at which the prestress was applied was kept constant at $179^{\circ} \mathrm{C}$ and the level of the prestress was altered. In the second set of experiments, the level of the prestress was constant throughout at $90 \mathrm{MPa}$ and the prestressing temperature was altered. In both sets of tests, specimens with precracks $85 \mu \mathrm{m}$ deep were loaded at a temperature above $T_{c}\left(120^{\circ} \mathrm{C}\right.$ for these test conditions) and at a strain rate of $5.9 \times 10^{-5} \mathrm{sec}^{-1}$ to a stress lower than the fracture stress at the testing temperature, immediately unloaded at a strain rate of $-5.9 \times 10^{-4} \mathrm{sec}^{-1}$ and allowed to cool in air to room temperature (initial cooling rate $-4^{\circ} \mathrm{Cmin}^{-1}$ ) before being reloaded to fracture at the initial strain rate of

The fracture surfaces of all the specimens tested were etched at room temperature in (saturated $\left.\mathrm{NH}_{4} \mathrm{Cl}\right): \mathrm{H}_{2} \mathrm{O}: \mathrm{H}_{2} \mathrm{SO}_{4}(3: 1: 1)$ at room temperature ${ }^{12}$ in order to reveal dislocation positions around the crack front. One specimen was fractured by impact in the four point bend jig at $77 \mathrm{~K}$ and then etched, so as to examine the state of the pre-crack before any testing.

\section{RESULTS}

\section{A. BRITTLE-DUCTILE TRANSITIONS}

\section{(1) $85 \mu \mathrm{m}$ precrack, impact loaded at $77 \mathrm{~K}$}

A specimen was mounted in the four-point bend jig, which was immersed in liquid nitrogen. The specimen was fractured by tapping the upper roller holder with a light hammer. Figures $3 \mathrm{a}$ and $3 \mathrm{~b}$ show, respectively, the unetched and etched fracture surface of this specimen. In figure $3 a$ the depth and form of the precrack can be seen. "River lines" originate directly from the precrack, indicating that no crack growth occurred before fracture. On etching, dislocations can be seen on all slip planes (the grown in dislocation density is low, at $\sim 5 \times 10^{5} \mathrm{~cm}^{-2}$ ). Near the tensile surface, there is a high density of dislocations on the (110) planes (normal to the tensile surface, slip traces vertical on the figure) that penetrate to a depth roughly that of the precrack. There is some evidence that a limited amount of slip has occurred also on the (1 $\overline{1} 0)$ plane parallel to the tensile surface (horizontal etch traces). Slip on the other planes $((011),(0 \underline{1} 1),(101),(\underline{1} 01))$, though not as intense as on the $(1 \underline{\overline{1}} 0)$ plane, penetrates more deeply into the specimen. These dislocations are those generated by the scribing process; it is unlikely that rapid crack propagation at this low temperature 
significantly modifies the slip bands. Thus any crack propagation at higher temperatures is into material with a relatively high dislocation density.

\section{(2) $55 \mu \mathrm{m}$ precrack, tested at $5.9 \times 10^{-6} \mathrm{sec}^{-1}$}

At room temperature, the load-displacement curve, is as shown in figure $4 \mathrm{a}$. The curve passes through a point of maximum slope (the "bendover point") at 97MPa. Assuming the initial positive curvature is due to settling of the apparatus combined with some plastic deformation under the rollers, this indicates that above a load of $97 \mathrm{MPa}$, plastic deformation of the centre span of the specimen or crack extension (lowering the specimen's compliance) is occurring, or both. Specimens ultimately fractured at 120MPa. The fracture was found to have initiated at the precrack, on the (001) fracture plane. A fracture surface is shown in figure 5a. This shows the initial precrack and a distinct large triangular region of stable crack growth emanating from the precrack, extending to a maximum depth of $280 \mu \mathrm{m}$. "River lines" originating from the edge of the stable crack growth region indicate that fast fracture had initiated here. The stable crack growth region contains a high density of linear crack steps lying along $<100>$ directions, at $45^{\circ}$ to the vertical on the figures (some steps are also visible near to and roughly parallel to the original precrack).

After etching the fracture surface, three distinct regions of dislocation patterns can be seen (figure 5b);

1. dislocations generated during the precracking, of the two types shown in figure $3 \mathrm{~b}$;

2. a high density of dislocations, on the $(011),(0 \underline{1} 1),(101)$ and $(\overline{1} 01)$ planes, within the region of stable crack growth, in linear arrays;

3. a distinct border of high dislocation density between the region of stable crack growth and the fast fracture region.

Taking the depth of the region of stable crack growth as the flaw depth at which final fracture occurred, and applying equations (2)-(4) (i.e. neglecting any modification due to the crack extension not extending to the full specimen width), the critical stress intensity at fast fracture was $3.93 \mathrm{MPa} \sqrt{\mathrm{m}}$.

On raising the testing temperature to $146^{\circ} \mathrm{C}$, the stress to fracture was found to decrease slightly. All stress - displacement curves showed a "bendover point", indicating that stable crack growth had occurred. The fracture surfaces showed the same general features before and after etching as those shown in figs. 5a and $5 \mathrm{~b}$. In Table I, fracture stress, crack extension and stress intensity are shown for each test temperature. The value of $\mathrm{K}_{\mathrm{F}}$, the critical stress intensity at fast fracture, is found to increase rapidly with temperature. As $\mathrm{K}_{\mathrm{F}}$ increases, a 
greater extent of crack growth can be accommodated before fast fracture. It is also possible that the rate of stable crack growth increases with temperature.

\section{(3) $85 \mu \mathrm{m}$ precrack, tested at $5.9 \times 10^{-6} \mathrm{sec}^{-1}$}

The room temperature load-displacement curve, shown in figure $4 \mathrm{~b}$, begins to decrease in slope at $\sim 80 \mathrm{MPa}$; fracture occurs at $88 \mathrm{MPa}$. The fracture surface exhibits a region of stable crack growth, extending to a depth of $230 \mu \mathrm{m}$ from the top of the precracked surface. Etching the surface reveals a similar dislocation distribution to that for the room temperature tests with the smaller precrack. $\mathrm{K}_{\mathrm{F}}$ is $2.52 \mathrm{MPa} \sqrt{\mathrm{m}}$., lower than the value for the smaller crack size.

\section{(4) $85 \mu \mathrm{m}$ precrack, tested at $5.9 \times 10^{-5} \mathrm{Sec}^{-1}$}

At room temperature, the load-displacement curve no longer displays any regions of decreasing slope, (figure 4c), i.e. an apparently completely "brittle" fracture has occurred, initiated at the precrack at $87 \mathrm{MPa}$. The unetched fracture surface (figure 6a) shows no signs of the stable crack extension seen at the lower strain rate; however, etching reveals that some stable crack growth has occurred, extending to a total depth of $140 \mu \mathrm{m}$ (figure $6 \mathrm{~b})^{*}$. Lines of dislocations in $\langle 100\rangle$ directions identify this region of stable crack growth, though the dislocation density within the stable crack growth region is much lower than that in figure $5 \mathrm{~b}$. Using the tip of the region of stable crack growth as the flaw depth at fracture, $\mathrm{K}_{\mathrm{F}}$ is $1.89 \mathrm{MPa} \sqrt{\mathrm{m}}$., approximately half that for specimens with the shallower crack tested at the lower loading rate.

Testing was carried out at elevated temperatures in the range $90-180^{\circ} \mathrm{C}$. Specimens tested at temperatures below $120^{\circ} \mathrm{C}$ showed a linear load-displacement curve similar to that of the room temperature test. At and above $122^{\circ} \mathrm{C}$, the load-displacement curve was of the form found in the experiments at the lower strain rate, i.e. the slope of the curve decreases (above a "bendover" stress). Fracture was found to occur at approximately the same stress ( 90MPa) at all temperatures, though with some scatter.

The etched fracture surfaces of specimens tested below $120^{\circ} \mathrm{C}$ all exhibited a small degree of stable crack growth similar to that found in room temperature tests for this crack length and strain rate. However, with

\footnotetext{
${ }^{*}$ It is interesting to note that this is roughly the depth $(160 \mu \mathrm{m})$ at which $\alpha$ in equation 4 begins to rise steadily. While we believe that the extent of stable crack growth is essentially controlled by the balance between several dislocation processes (see below), this rise in $\alpha$ may also be a factor in the balance.
} 
increasing temperature above $122^{\circ} \mathrm{C}$, the extent of the stable crack growth increased. The variation with temperature of $\mathrm{K}$ at "bendover" and of $\mathrm{K}_{\mathrm{F}}$, calculated from the final crack lengths, is shown in figure 7 . $\mathrm{K}_{\mathrm{F}}$ remains at an approximately constant level of $1.85 \mathrm{MPa} \sqrt{\mathrm{m}}$, until a temperature of approximately $120^{\circ} \mathrm{C}$, where it begins to increase steadily with temperature.

The etched fracture surfaces shown in figure 8 show the same general features as those from tests at lower strain rates (figure 5), i.e. intense shallow slip on planes normal to the surface near the pre-crack initiating scribing track, less intense but deeper slip on the other slip planes, more intense slip on these planes within the crack growth region, and a dense line of dislocations that mark the final extent of stable crack growth. In figure $8 \mathrm{~b}$, etch pits due to grown-in dislocations $\left(\sim 5 \times 10^{5} \mathrm{~cm}^{-2}\right)$ can be seen in the lower part of the figure.

\section{B. WARM-PRESTRESSING EFFECT}

For the specimens with the larger precracks tested at the higher strain rate, $\mathrm{K}_{\mathrm{F}}$ increases with increasing temperature above $120^{\circ} \mathrm{C}$; we interpret this as being due to the influence of shielding dislocations. Stable crack growth increases in extent with increasing temperature. Warm prestressing experiments were performed to investigate the influence of dislocation arrays developed at high temperature on the room temperature $\mathrm{K}_{\mathrm{F}}$ and stable crack growth.

\section{(1) Constant prestressing temperature, varying prestress}

The temperature for this set of tests was $179^{\circ} \mathrm{C}$; this is well within the high temperature regime ( $\sim 120^{\circ} \mathrm{C}$ and above) where $\mathrm{K}_{\mathrm{F}}$ is higher than at room temperature and where a large amount of stable crack growth occurs. The prestress ranged between 50 and 104MPa, i.e. from below to well above the normal room temperature fracture stress $(87 \mathrm{MPa})$. Figure 9 shows a typical pair of stress-displacement curves for the prestressing and the room temperature fracture tests. The bendover stress at $179^{\circ} \mathrm{C}$ is $60 \mathrm{MPa}$, thus prestressing to less than 60MPa did not give a "bendover" point in the high temperature loading. However, all subsequent room temperature fracture test curves, whatever the level of prestress, did show a "bendover" point.

Results are summarised in Table II. Below a prestressing $\mathrm{K}$ of $1.2 \mathrm{MPa} \sqrt{\mathrm{m}}$ (equivalent to a prestress of $60 \mathrm{MPa}$ with typical crack growth on prestressing), $\mathrm{K}$ at final fracture is $\sim 2.1 \mathrm{MPa} \sqrt{\mathrm{m}}$, compared to 
$\sim 1.89 \mathrm{MPa} \sqrt{\mathrm{m}}$ with no prestressing. Above this level of prestress, $\mathrm{K}_{\mathrm{F}}$, based on the final crack size, increases to $\sim 2.7 \mathrm{MPa} \sqrt{\mathrm{m}}$. This value is approximately the same whatever the value of the prestress above $1.2 \mathrm{MPa} \sqrt{\mathrm{m}}$.

All the unetched fracture surfaces show four distinct crack regions (figures 10a, c \& e): (i) the precrack; (ii) stable crack growth occurring during the prestress; (iii) stable crack growth occurring during the room temperature fracture test; (iv) fast fracture. The overall crack depth shows no trend with level of prestress above 1.2 MPa $\sqrt{\mathrm{m}}$, with a mean value of $145 \mu \mathrm{m}$. (Table II); this is not significantly different from the total crack depth following stable crack growth in room temperature fracture tests performed without any warmprestressing $(140 \mu \mathrm{m})$. However, the density of dislocations in the crack extension zone is much greater after any warm prestressing treatment than after simple room temperature tests. (Compare figure $10 \mathrm{~b}$ with figure $6 \mathrm{~b}$ ).

Thus warm prestressing to above a critical stress intensity level (60MPa) at a fixed temperature $\left(179^{\circ} \mathrm{C}\right)$ just above the "transition temperature" increases the room temperature $\mathrm{K}_{\mathrm{F}}$ but does not significantly change the extent of stable crack growth.

\section{(2) Constant prestress, varying prestressing temperature.}

With the prestress kept constant at 90MPa (a value above the "bendover" stress, at which the stressdisplacement curve begins to decrease in slope) the prestressing temperature was varied between $161^{\circ} \mathrm{C}$ and $199^{\circ} \mathrm{C}$. Results are shown in Table III. With increasing temperature, more crack growth occurs during prestressing, so that the prestressing $\mathrm{K}$ increases. On testing at room temperature, $\mathrm{K}$ at fracture increases with increasing prestressing temperature; both were at levels higher than for specimens fractured at room temperature without any prestressing* ${ }^{*}$ The fracture surfaces had the same four crack regions as in the previous warm-prestressing experiments, i.e. (1) initial precrack, (2) growth under prestress and (3) growth at room temperature before (4) fast fracture. The overall depth of the crack at the end of stage (3) increased with increasing temperature for temperatures above $\sim 170^{\circ} \mathrm{C}$ (ranging from 150 to $250 \mu \mathrm{m}$ ), due primarily to increased crack growth at room temperature (i.e. in stage (3)).

An additional test was performed in which a specimen was prestressed to $80 \mathrm{MPa}$ at $179^{\circ} \mathrm{C}$ and cooled to room temperature, then broken in four point bend by impact at liquid nitrogen temperature. On the etched fracture surface, there is a region of stable crack growth corresponding to the prestress, but there is no stable crack growth from the liquid nitrogen temperature test.

\footnotetext{
${ }^{*}$ The anomalous result at $161^{\circ} \mathrm{C}$ appears to results from a deeper precursor flaw $(100 \mu \mathrm{m}$ rather than $85 \mu \mathrm{m})$
} 
Thus warm prestressing to a fixed stress level (90MPa) with varying temperature $\left(161-199{ }^{\circ} \mathrm{C}\right)$ increases the room temperature $\mathrm{K}_{\mathrm{F}}$ and increases the total extent of stable crack growth; this increase in crack growth is mostly due to enhanced crack growth at room temperature rather than during the prestressing cycle.

\section{MICROSTRUCTURAL STABILITY}

It is possible that microstructural changes with temperature (e.g. precipitation effects) could have affected the above results by altering dislocation mobility. This was checked by experiments in which specimens were indented at room temperature and etched to reveal dislocation positions; they were then heated to $200^{\circ} \mathrm{C}$ (the highest temperature at which fracture testing was performed) for 4 hours, cooled and then reindented and etched. Dislocation array lengths were compared; if thermally-induced microstructural changes had altered the dislocation mobility this would be reflected in different dislocation array lengths around the indents. The arrays were all of the same size $(160 \pm 20 \mu \mathrm{m}$ at $200 \mathrm{~g})$. This shows that the change in dislocation velocity due to annealing effects is minimal, so the BDT and WPSE are due to the inherent variation in the dislocation velocity with temperature, not to (permanent) microstructural changes in the crystal with temperature.

\section{DISCUSSION}

\section{(1) Stable Crack Growth}

Stable crack growth (SCG) is a significant factor in the fracture and WPSE behaviour of single crystal MgO. SCG is also observed in single crystal molybdenum ${ }^{7}$, but silicon ${ }^{5}$ and sapphire ${ }^{8}$ crystals show no stable crack growth ${ }^{*}$. We believe that this is because in $\mathrm{MgO}$, as in molybdenum, dislocations are relatively mobile at the testing conditions used, so that precracks cannot be introduced without producing dislocations near the crack tip, whereas in $\mathrm{Si}$ and $\mathrm{Al}_{2} \mathrm{O}_{3}$ crack tips which are effectively dislocation-free can be produced by indentation.

The interaction of the crack tip with these dislocations gives rise to stable crack growth. When a large degree of SCG occurs, there are crystallographically-aligned cleavage features in the crack growth region (a

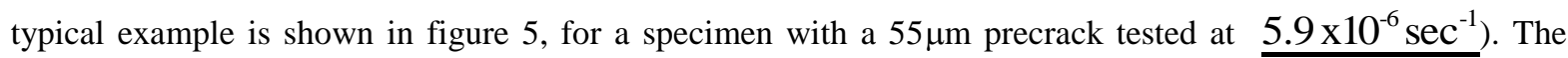

\footnotetext{
${ }^{*}$ though it it commonly found in polycrystalline ceramics ${ }^{13-15}$, and in glass ${ }^{16}$.
} 
nature of the fracture surfaces indicate that the crack advance occurs by a process of repeated microcleavage. Since the stress / strain curves appear smooth at all stages of the tests, such processes must be occurring on a very fine scale.

On etching, the crack advance region is seen to contain a high density of dislocations in well defined slip bands, corresponding closely to the cleavage features. These terminate at a band of very high dislocation density at the final position of the stably advancing crack tip before fast fracture occurs. The higher density of dislocations within the crack growth zone, and the dense band of dislocations along the crack front, suggest that the microcleavage processes are associated with dislocation motion. Since no SCG occured in the impact test at 77K (when dislocations will be effectively immobile in the timescale of the test) and because the extent of SCG generally increases with increasing temperature (and with decreasing strain rate), we conclude that the crack advance mechanism requires the dislocations to operate. (Such a variation with temperature and strain rate would not occur were the SCG simply a result of the interaction between applied stress and residual stresses from the scratching process.) We therefore propose the mechanism ${ }^{+}$for crack advance illustrated in figure 11 , where the crack advances by small-scale microcleavage as follows:

1. A dislocation source at or very close to the crack tip emits dislocation half-loops. These will rapidly spread along the tip.

2. At a step in the crack front, the dislocation loops will expand round to the "underside" of the crack . The segments of the loops that have advanced beyond the crack step are antishielding to the crack at and beyond the step (i.e. they increase the local stress intensity).

3. When enough dislocations have looped round the step, the stress intensity at the step will exceed $\mathrm{K}_{1 \mathrm{c}}$. The step will advance, absorbing the antishielding dislocations; any antishielding dislocations "below" the crack plane will be attracted to the crack tip and absorbed. The process can then begin again.

This process, repeated at every crack step, gives rise to an overall crack advance. A result of this process is that there should be dislocation slip bands trailing behind the crack front, each band being associated with an "unzipping" crack step. This is what is seen experimentally.

\footnotetext{
+ Our thanks to Professor Sir Peter Hirsch (pers. comm.) for suggesting this mechanism.
} 
The extent of stable crack growth before final fast fracture occurs will thus be controlled by the balance between three factors:

1. The time variation of shielding by the more distant parts of the dislocation loops. The size of the shielding arrays will increase with time (at least in test where $\mathrm{K}$ is increasing), and their rate of growth will increase with temperature.

2. The rate of increase of applied stress intensity $(\underline{K})$. This will increase with strain rate and initial crack size, and will increase as the crack grows.

3. The rate at which antishielding dislocations are generated, and hence the rate of SCG. These dislocations are driven by the shielding loops closer to the dislocation source. The generation of these, and thus of the antishielding dislocations, will increase with temperature and $\underline{\mathrm{K}}$.

Fast fracture will occur when the local $\mathrm{K}$ at the crack tip $\left(\mathrm{K}_{\mathrm{e}}\right)$ exceeds $\mathrm{K}_{1 \mathrm{c}}$ even at stage 3 of the crack growth process (fig 11d), when all the antishielding dislocations have been absorbed following a crack jump. Because of the shielding dislocations, the applied $\mathrm{K}$ will be higher than $\mathrm{K}_{1 \mathrm{c}}$ at fracture.

Specimens with both crack sizes tested at the slower strain rate at room temperature showed substantial SCG. This is because $\underline{\mathrm{K}}$ is low, and there is time to develop a shielding array that keeps $\mathrm{K}_{\mathrm{e}}$ below $\mathrm{K}_{1 \mathrm{c}}$ until the crack has grown to many times the original depth. The specimen with the deeper original crack fails at a slightly shallower final crack size $(230 \mu \mathrm{m})$ than the specimen with the shallower original crack (fails at $280 \mu \mathrm{m})$. This may indicate that the greater initial $\mathrm{K}$ favours the crack advance process more than shielding. On raising the testing temperature, the shielding array can develop more rapidly, and increased dislocation activity near the crack tip enhances the crack growth process. The result is a large increase in $\mathrm{K}_{\mathrm{F}}$, with a slight increase in stress to fracture and much increased crack growth.

Specimens with the larger precrack tested at the higher strain rate showed only a very limited amount of SCG at room temperature, not visible as a non-linearity of the stress-strain curve, but detectable after etching of the fracture surface. This "near-brittle" behaviour occurs because the rate of increase of shielding from the dislocation array cannot compensate for the rate of increase of applied stress intensity at this strain rate (especially after some crack growth has occurred). With increasing temperature, the increasing dislocation mobility enhances the dislocation-controlled microcleavage (from the motion of the near-crack-tip antishielding part of the dislocation loops) and also leads to more rapid initial shielding. It appears that above $\sim 120^{\circ} \mathrm{C}$, there is enough shielding to prevent unstable crack growth until a substantial amount of SCG has occurred. There is 
also some evidence from figure 8 that the density of slip lines within the crack profile increases with increasing temperature; thus SCG may be enhanced by an increase in the number of active slip planes as the temperature is raised.

The final shape of the crack tends to that of a triangle delineated by the intersections of the slip planes responsible for SCG with the fracture plane (e.g. see fig 5). This is because:

1. any initially curved crack front (e.g. as in fig. 6) will effectively contain a large number of ledges of the type shown in fig 11; these will eventually meet on the centre line of the specimen, having advanced in directions determined by the slip planes. Any further ledges will then presumably be initiated at the specimen edges;

2. The slip planes themselves will not easily interpenetrate, as locking reactions will occur at the intersections of the $(0 \overline{1} 1)$ or $(011)$ and the (101) or (101) slip plane. There is thus a tendency for slip planes more nearly parallel to the local crack front to dominate in each half of the specimen, promoting crack adavnce parallel to one direction only. (see fig 5a)

\section{(2) Warm Prestressing}

At a constant prestressing temperature, the extent of room temperature SCG does not vary in any consistent way with the prestress or with the original depth of the precrack; the total crack length of $136 \mu \mathrm{m} \pm$ $22 \mu \mathrm{m}$ is equivalent to that for non-prestressed specimens. However, the prestressed specimens show a point of maximum slope on their room temperature stress / strain curves, whereas "normal" low temperature tests did not. This is probably associated with a lowering of specimen compliance by plastic flow around the crack tip; there is a much greater density of dislocations visible around the cracks in the prestressed specimens.

The room temperature fracture stress intensity rises in a step from $\sim 2 \mathrm{MPa} \sqrt{\mathrm{m}}$ to $\sim 2.7 \mathrm{MPa} \sqrt{\mathrm{m}}$ for prestress levels above $\sim 1.2 \mathrm{MPa} \sqrt{\mathrm{m}}$ (a stress of $\sim 60 \mathrm{MPa}$, under these experimental conditions), and does not depend in any significant way on the level of prestress above this value or the extent of SCG. Thus a mechanism appears to be operating that can increase the crack tip shielding by a fixed amount but which does not affect the extent of SCG. This may be because the warm-prestressing above the critical level produces a constant amount of shielding via long-range dislocation interaction with the crack tip; the crack extension process is due to local dislocation processes, which will operate under this "umbrella" of shielding. Thus the 
transition to fast fracture will occur at roughly the normal amount of crack extension, but at a higher level of externally applied $\mathrm{K}$.

In the experiments where the prestressing temperature was varied, the amount of SCG and the room temperature fracture stress intensity increased consistently with prestressing temperature. This possibly results from an increase with increasing prestressing temperature in the number of activated dislocation sources near the crack tip, or in slip band width due to increased cross-slip (there is some indication of this in figure 10). Since slip bands, once activated, appear to operate at room temperature, an increased number of active slip planes will lead to an enhancement both of the local (antishielding) process causing the SCG and of the shielding from the more distant parts of the dislocation loops produced in prestressing that limit the extent of SCG before final fast fracture. Since this is also present in the specimens prestressed at $179^{\circ} \mathrm{C}$ to below the critical $\mathrm{K}$ for room temperature $\mathrm{K}_{\mathrm{F}}$ enhancement, it is probably the shielding effect of the dislocations produced by prestressing that is the more important.

The magnitude of the shielding depends primarily on the level of prestressing K. The effectiveness of the warm-prestressing process is shown in figure 12 . Here, data for all tests are shown as $\mathrm{K}_{\mathrm{F}}$ against crack length at fracture. Data for all simple fracture tests, whatever the temperature, initial precrack size or strain rate, fall within a reasonably well-defined band; data from warm-prestressing experiments show clearly the influence of additional crack shielding.

A full explanation of the warm-prestressing effect in materials where stable crack growth occurs, to enable prediction, for example, of the transition between stable crack growth and fast fracture, requires extension of the model of Hirsch et al. ${ }^{3}$ to describe the process illustrated in figure 11 . Work is in progress and will be reported elsewhere.

\section{CONCLUSIONS}

Four-point bend tests performed on precracked single crystals of $\mathrm{MgO}$ have shown:

1. The mechanism of stable crack growth in single crystal $\mathrm{MgO}$ is by microcleavage induced by antishielding dislocations from sources near to the crack tip. We have proposed a mechanism for this process.

2. The amount of stable crack growth exhibited by "semi-brittle" materials is highly dependent on strain rate and the density of dislocation sources at or near the crack tip. A slow strain rate 
enables the sources to emit many dislocations that can interact with the crack, shielding the crack tip, and thus allowing more stable crack growth.

3. At higher strain rates and low temperatures, the sources are unable to emit sufficient dislocations to shield the crack before the stress intensity at the crack tip reaches $\mathrm{K}_{1 \mathrm{c}}$, and so a "brittle" fracture occurs. However, on increasing the testing temperature to above $120^{\circ} \mathrm{C}$, dislocation emission occurs at a rate sufficient to shield the crack tip heavily, and a large amount of stable crack growth can occur before brittle fracture.

4. There is a warm prestressing effect (WPSE), in which the room temperature fracture toughness is increased by prior deformation at an elevated temperature. Warm prestressing cycles produce shielding, allowing a greater extent of stable crack growth at room temperature at high stress intensity increase rates.

5. The WPSE is only found above a critical level of prestress at a given temperature. The enhancement of room temperature fracture stress intensity increases with increasing prestressing temperature, as previously reported in silicon ${ }^{6}$, since the dislocation nucleation rate is highly temperature dependent, but does not increase with increasing prestress above the critical level.

6. Taken in combination with studies of brittle-ductile transitions in other materials ${ }^{3,5,7,8}$, this study demonstrates the importance of dislocation arrangements near the crack tip in controlling the form and temperature of the brittle-ductile transition.

\section{Acknowledgements}

The authors gratefully acknowledge the contributions of Professor Sir Peter Hirsch and Professor R. Thomson to the work reported here, and the helpful comments of the referees. 


\section{References}

${ }^{1}$ J. R. Rice and R. Thomson, "Ductile versus Brittle Behaviour of Crystals" Phil. Mag. 29, 73-97, (1974).

${ }^{2}$ B. S. Majumdar and S. J. Burns, "Crack Tip Dislocations in MgO" Scripta Metall.14, 653-656, (1980).

${ }^{3}$ P. B. Hirsch, S. G. Roberts and J. Samuels, "The Brittle-Ductile Transition in Silicon. II. Interpretation", Proc. R. Soc. Lond. A 421, 25-53, (1989).

${ }^{4}$ P.D. Warren, "The Brittle-Ductile Transition in Silicon: the Influence of Pre-existing Dislocation Arrangements" Scripta Metall. 23, 637-642, (1989).

${ }^{5}$ J. Samuels and S. G. Roberts "The Brittle-Ductile Transition in Silicon. I. Experiments" Proc. R. Soc. Lond. A 421, 1-23 (1989).

${ }^{6}$ A. S. Booth, M. Cosgrave and S. G. Roberts, "The Warm-Prestressing Effect in Silicon" Acta metall. mater. 39, 191-197 (1991).

${ }^{7}$ M. Ellis, "The Ductile to Brittle Transition in Molybdenum" D.Phil Thesis, University of Oxford (1991).

${ }^{8}$ S. G. Roberts, H. S. Kim and P. B. Hirsch, "The Brittle-Ductile Transition in Silicon and Sapphire" in Proceedings of $9^{\text {th }}$ International Conference on Strength of Metals and Alloys, Haifa, Israel (1991) .

${ }^{9}$ M.J. Lii, X.F. Chen, Y. Katz and W.W. Gerberich, "Dislocation Modeling and Acoustic Emission Observation of Alternating Ductile/Brittle Events in Fe-3wt\%Si Crystals", Acta metall. mater, 38, 2435-2453 (1990).

${ }^{10}$ S. M. Weiderhorn, R. L. Moses and B. L. Bean, "Plastic Deformation and the Fracture Surface Energy of Sodium Chloride", J. Am. Ceram. Soc., 53, 18-23 (1970).

${ }^{11}$ W. F. Brown and J. E. Srawley, "Plane Strain Crack Toughness Testing of High Strength Metallic Materials", ASTM STP 410, (1966)

${ }^{12}$ S. G. Roberts, "Knoop Hardness Anisotropy and Predicted and Observed Slip Patterns in MgO" Phil. Mag., 58, 347-364 (1988).

${ }^{13}$ A. G. Evans and S. M. Wiederhorn, "Crack Propagation and Failure Prediction in Silicon Nitride at Elevated Temperatures" J. Mat. Sci., 9, 270-278 (1974).

${ }^{14}$ A. G. Evans and F. F. Lange, "Crack Propagation and Fracture in Silicon Carbide" J. Mat. Sci., 10, 16591664 (1975).

${ }^{15}$ P. F. Becher, "Subcritical Crack Growth in Partially Stabilised $\mathrm{ZrO}_{2}$ (MgO)" J. Mater. Sci., 21, 297-300 (1984).

${ }^{16}$ D. K. Shetty and A. R. Rosenfield, "Slow Crack Growth in Glass in Combined Mode I and Mode III Loading" Scripta metall. mater., 25, 997-1002 (1991). 
Table I. Specimens with 55- $\mu \mathrm{m}$ Precrack, Tested at $5.9 \times 10^{-6} \mathrm{~s}^{-1}$

\begin{tabular}{|c|c|c|c|c|c|c|c|c|}
\hline \multirow[b]{2}{*}{$\begin{array}{l}\text { Temp } \\
\left({ }^{\circ} \mathrm{C}\right)\end{array}$} & \multicolumn{4}{|c|}{ "Bendover" } & \multicolumn{4}{|c|}{ Fracture } \\
\hline & $\begin{array}{l}\text { Load } \\
\text { (N) }\end{array}$ & $\begin{array}{l}\text { Stress } \\
\text { (MPa) }\end{array}$ & $\begin{array}{c}\text { Crack } \\
\text { size }(\mu \mathrm{m})\end{array}$ & $\begin{array}{c}K \\
\left(\mathrm{MPa} \cdot \mathrm{m}^{1 / 2}\right)\end{array}$ & $\begin{array}{l}\text { Load } \\
\text { (N) }\end{array}$ & $\begin{array}{l}\text { Stress } \\
\text { (MPa) }\end{array}$ & $\begin{array}{c}\text { Crack } \\
\text { size }(\mu \mathrm{m})\end{array}$ & $\begin{array}{c}K_{\mathrm{r}^{\prime}} \\
\left(\mathrm{MPa} \cdot \mathrm{m}^{1 / 2}\right)\end{array}$ \\
\hline 20 & 31 & 109 & 55 & 1.52 & 33 & 122 & 280 & 4.0 \\
\hline 72 & 32 & 112 & 55 & 1.57 & 33.5 & 115 & 315 & 4.1 \\
\hline 146 & 23 & 81 & 55 & 1.13 & 32 & 112 & 650 & 11.2 \\
\hline
\end{tabular}

Table Il. Warm Prestressing-Variation with Prestress at Fixed Temperature $\left(179^{\circ} \mathrm{C}\right)^{*}$

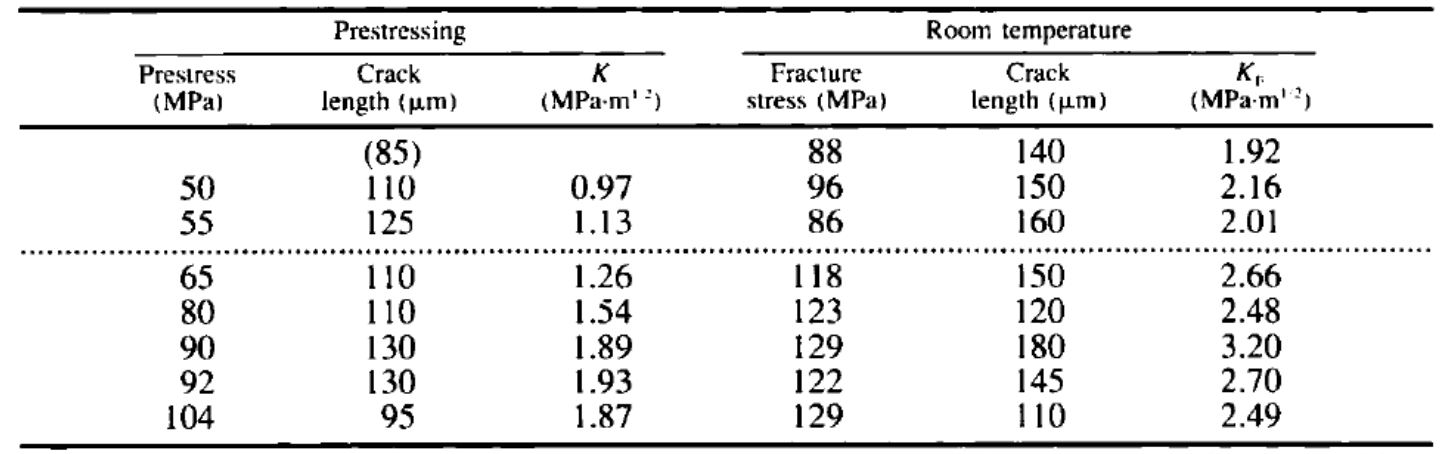

"The broken line between prestress values of 55 and 65 MPa indicates the level of "bendover stress" for these conditions. i.e.. the stress at which we assume stable crack growth begins.

Table III. Warm Prestressing-Variation with Temperature at Fixed Prestress

\begin{tabular}{|c|c|c|c|c|c|c|}
\hline \multirow{2}{*}{$\begin{array}{l}\text { Prestressing } \\
\text { temperature } \\
\left({ }^{\circ} \mathrm{C}\right)\end{array}$} & \multicolumn{3}{|c|}{ Prestressing } & \multicolumn{3}{|c|}{ Room temperature } \\
\hline & $\begin{array}{l}\text { Prestress } \\
\text { (MPa) }\end{array}$ & $\begin{array}{c}\text { Crack } \\
\text { length }(\mu \mathrm{m})\end{array}$ & $\begin{array}{c}K \\
\left(\mathrm{MPa} \cdot \mathrm{m}^{\prime}\right.\end{array}$ & $\begin{array}{c}\text { Fracture } \\
\text { stress (MPa) }\end{array}$ & $\begin{array}{c}\text { Crack } \\
\text { length }(\mu \mathrm{m})\end{array}$ & $\begin{array}{c}K_{1} \\
\left.\left(\mathrm{MPa}^{\prime} \cdot \mathrm{m}^{\prime} \cdot\right)^{\prime}\right)\end{array}$ \\
\hline (None) & & $(85)$ & & 88 & 140 & 1.92 \\
\hline 161 & 90 & 150 & 2.03 & 123 & 180 & 3.06 \\
\hline 170 & 90 & 115 & 1.78 & 125 & 135 & 2.67 \\
\hline 179 & 90 & 130 & 1.89 & 129 & 180 & 3.21 \\
\hline 190 & 90 & 135 & 1.92 & 137 & 200 & 3.61 \\
\hline 199 & 90 & 150 & 2.03 & 147 & 250 & 4.45 \\
\hline
\end{tabular}




\section{FIGURES}

a)

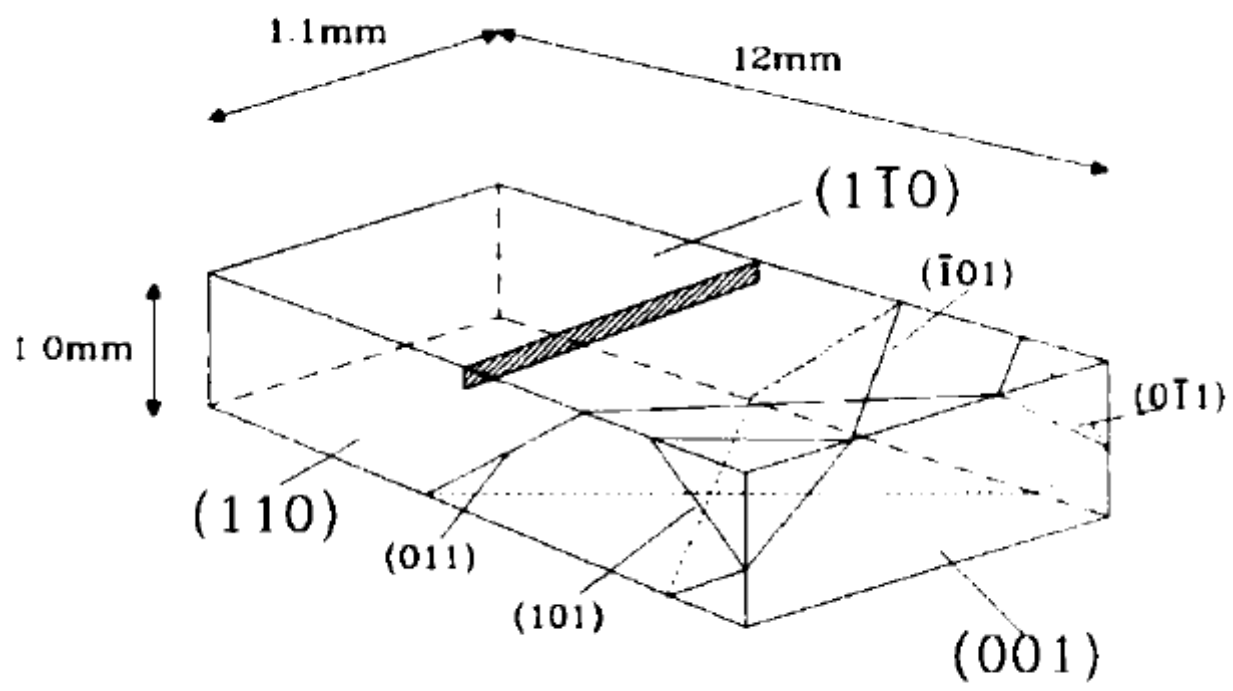

b)

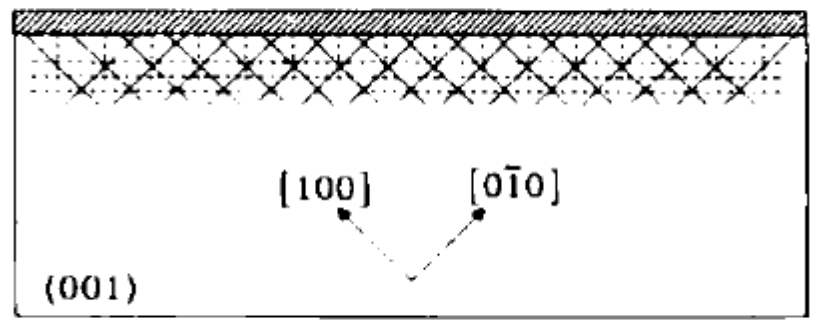

1 (a) Orientation of slip planes and precrack (shaded) within the specimens. Two pairs of slip planes, $(101) \&\left(\underline{1}^{01}\right)$ and $(011) \&(0 \underline{1} 1)$, produce the same slip traces along $\langle 100\rangle$ directions on the (001) fracture plane.

(b) Possible slip traces on the fracture plane. Traces of slip planes normal to the fracture plane are shown as dotted lines; traces of slip planes inclined to the fracture plane are shown as solid lines. 


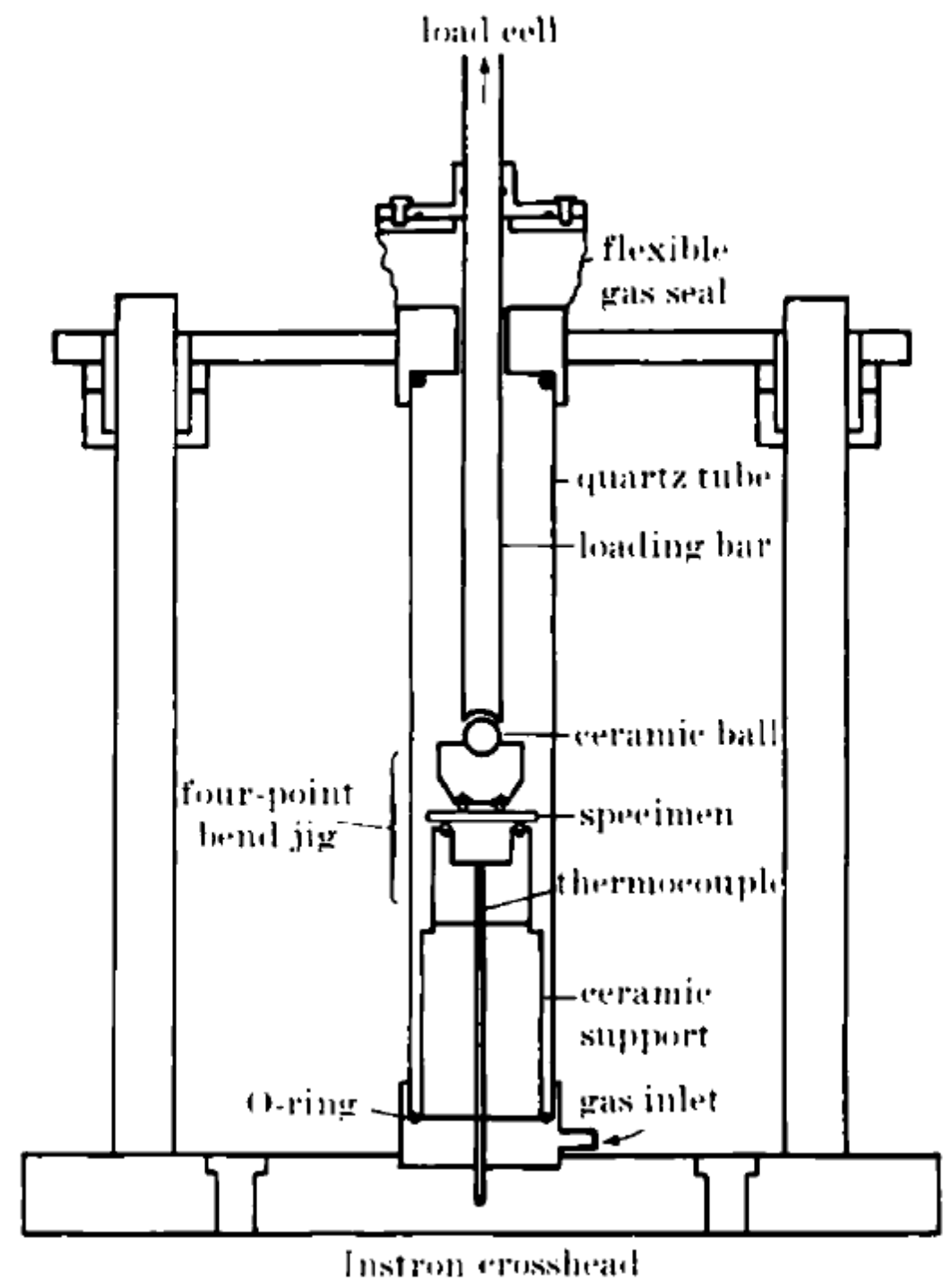

2. Testing apparatus. The roller spacings in the four-point bend jig are $10 \mathrm{~mm}$ and $5 \mathrm{~mm}$. 

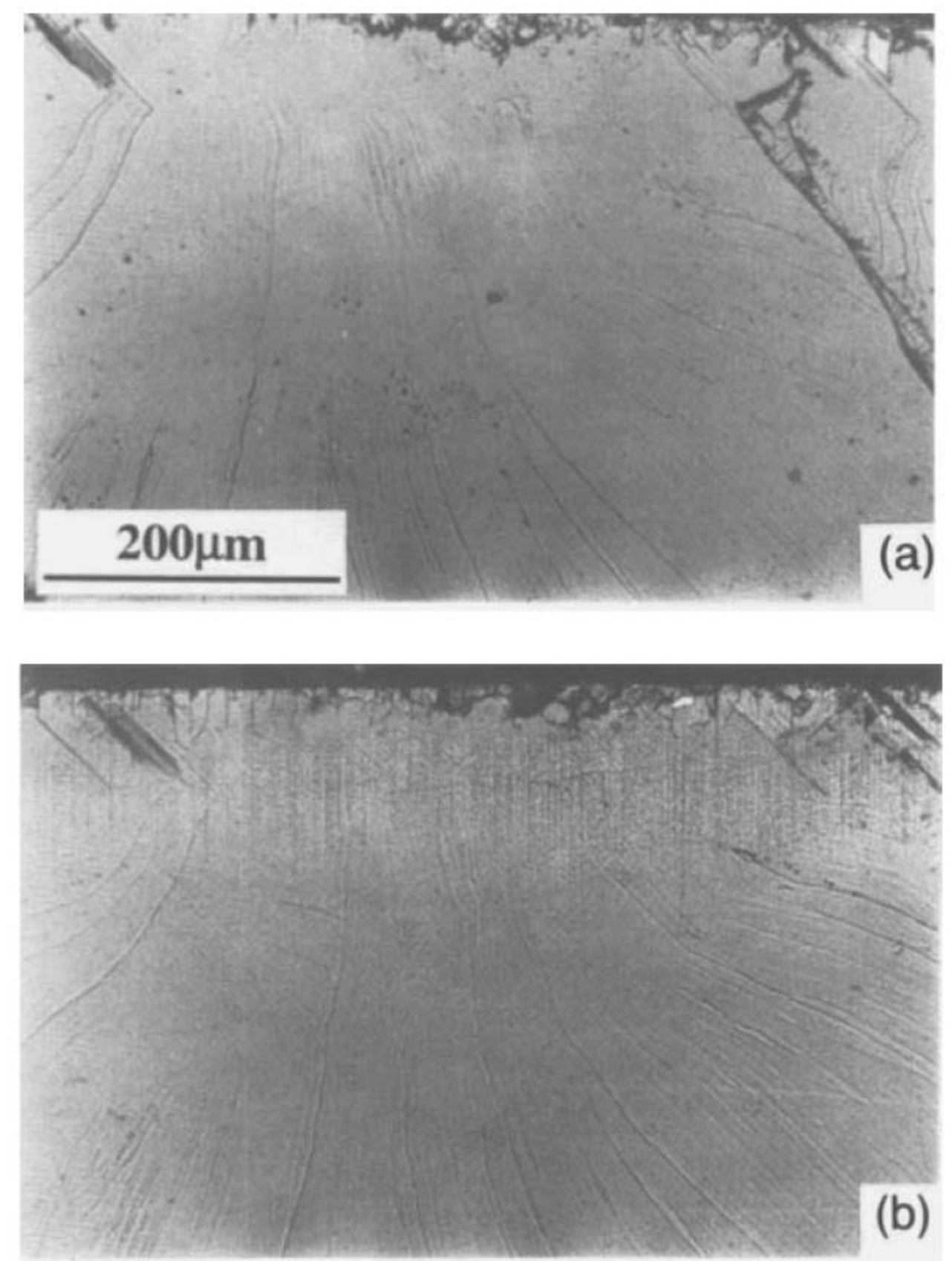

3. (a) unetched and (b) etched fracture surfaces of specimen with an $85 \mu \mathrm{m}$ deep precrack loaded in four-point bend by impact at 77K. Fracture has started immediately from the precrack. Dislocations, introduced by the scratching to produce the precrack, can be seen on all orientations of slip plane. 


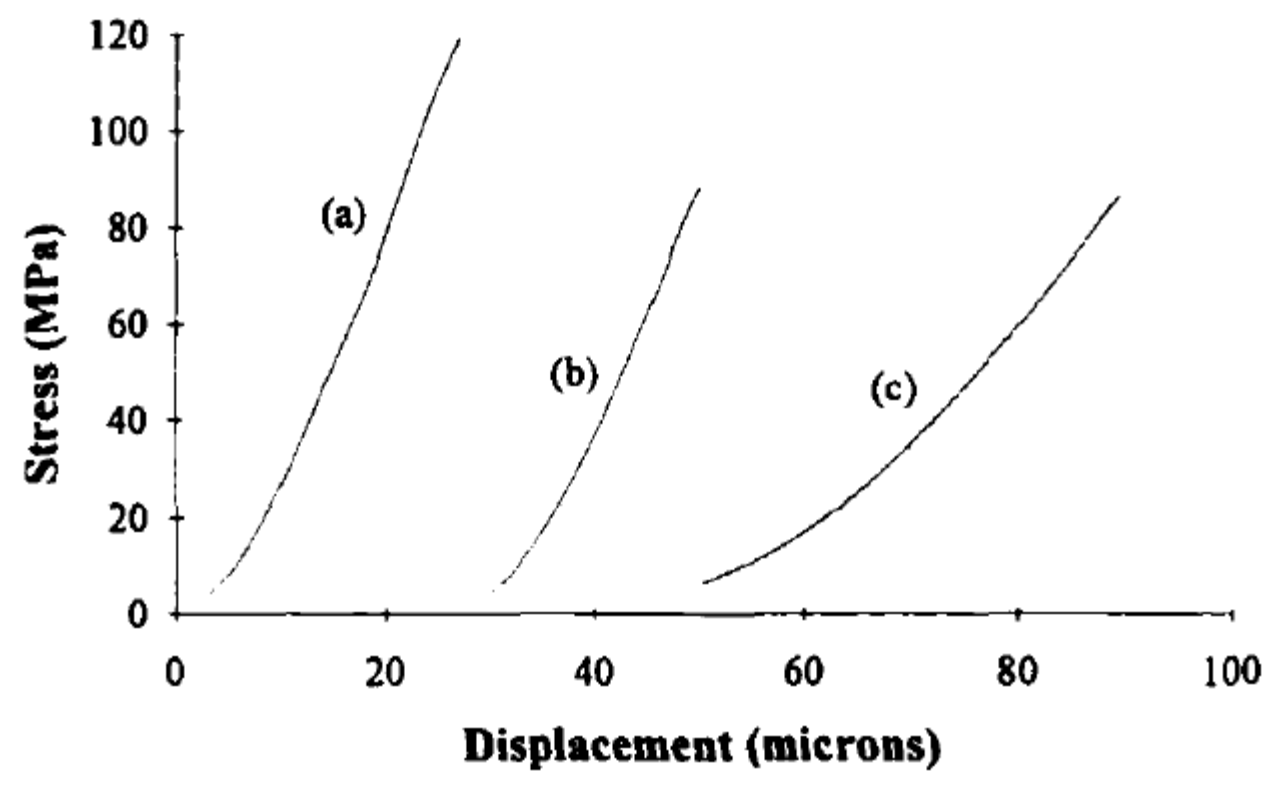

4. Load-displacement curves for specimens tested at room temperature:(a) strain rate $5.9 \times 10^{-6} \mathrm{sec}^{-1}$, precrack depth $55 \mu \mathrm{m}$,

(b) strain rate $5.9 \times 10^{-6} \mathrm{sec}^{-1}$, precrack depth $85 \mu \mathrm{m}$,

(c) strain rate $5.9 \times 10^{-5} \mathrm{sec}^{-1}$, precrack depth $85 \mu \mathrm{m}$.

Settling of the apparatus gives the initial positive curvature of the stress / displacement curves. Tests at the lower strain rate show a region of downward curvature in the stress-strain curveat high stress; the test at the higher strain rate with the longer crack appears to behave elastically up until fracture 

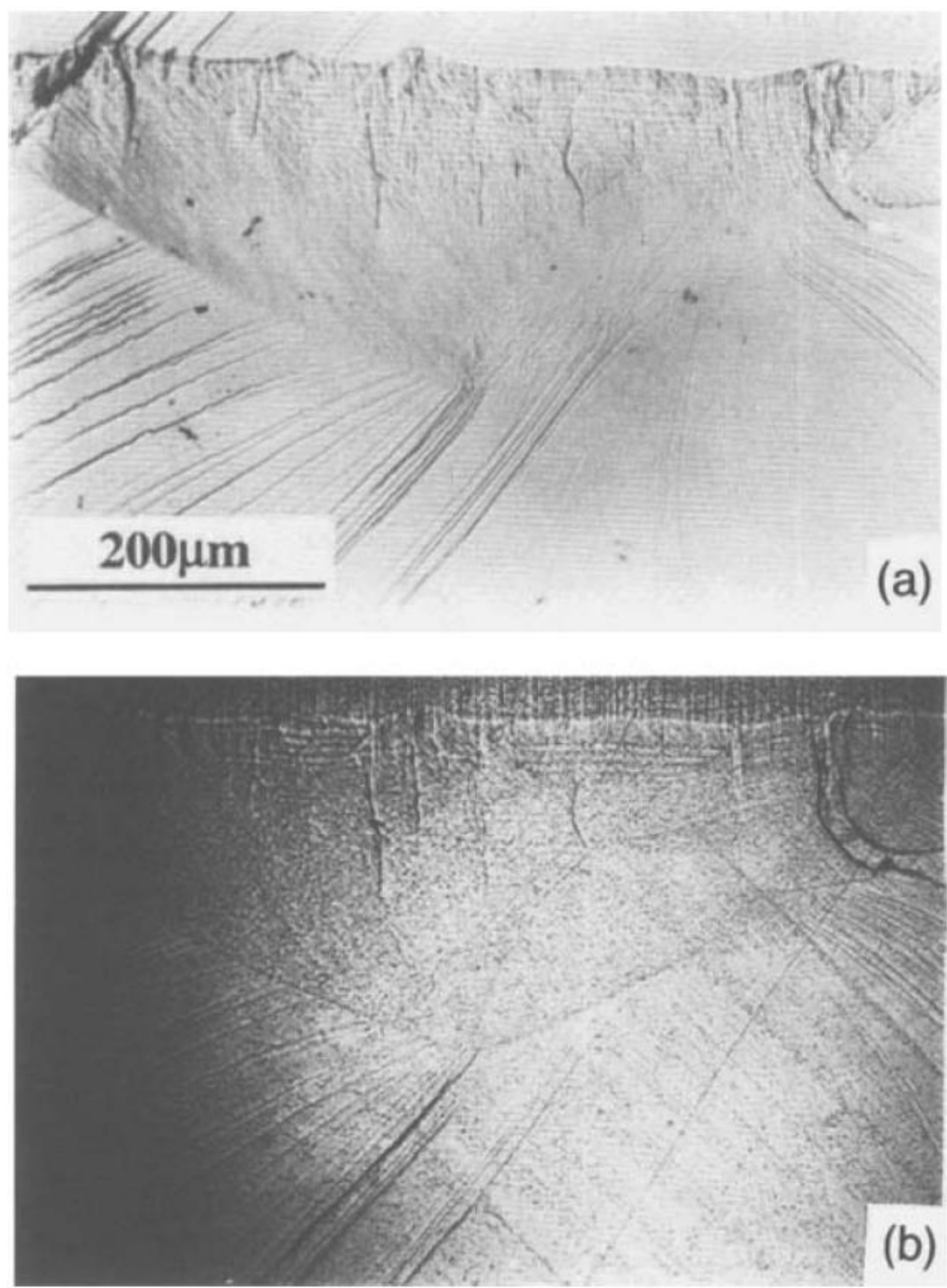

5. (a) Unetched and (b) etched fracture surface of a specimen fractured at room temperature at strain rate $5.9 \times 10^{-6} \mathrm{sec}^{-1}$ with a $55 \mu \mathrm{m}$ precrack. A large triangular region of stable crack growth can be seen. Steps within the crcak growth region on the unetched fracture surface correspond closely to lines of dislocation etch pits (along $<100>$ directions) on the etched fracture surface. 

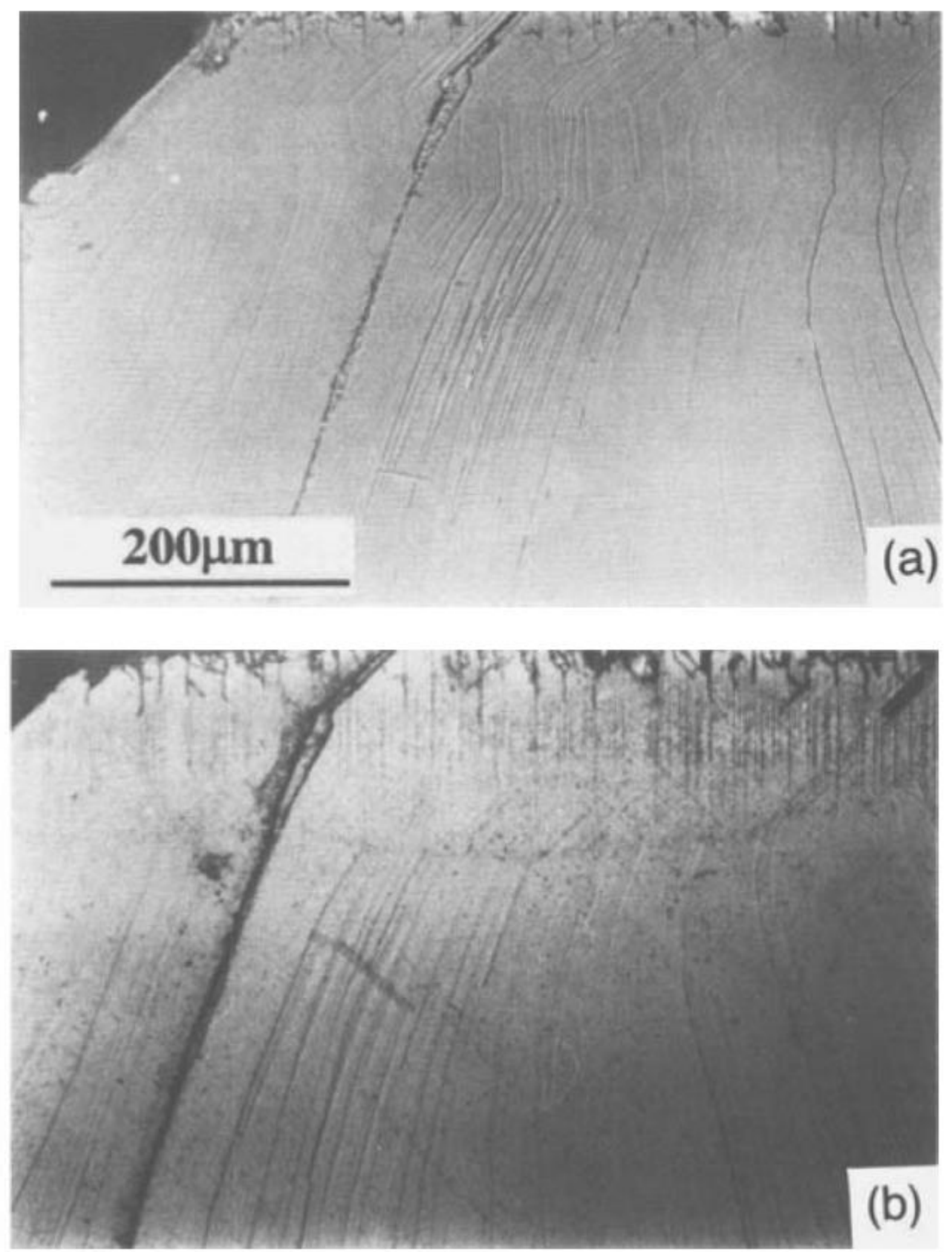

6. (a) Unetched and (b) etched fracture surface of specimen with an $85 \mu \mathrm{m}$ precrack, tested at room temperature at $5.9 \times 10^{-5} \mathrm{sec}^{-1}$. Note the very small region of stable crack growth. 


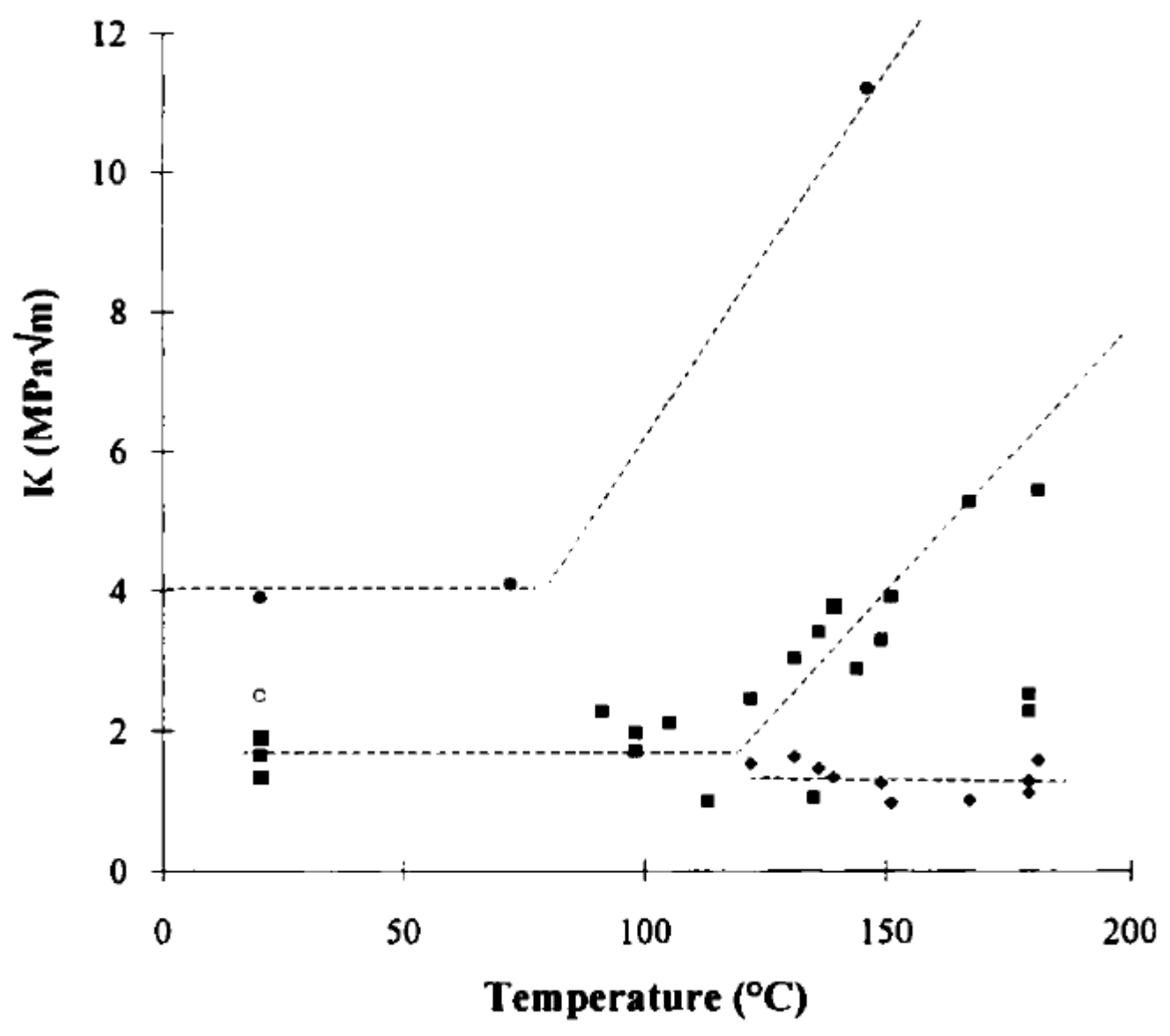

7. Fracture stress intensity vs. temperature for specimens containing a $85 \mu \mathrm{m}$ precrack tested at a strain rate of $5.9 \times 10^{-5} \mathrm{sec}^{-1}$. Where stress / strain curves showed a point of maximum slope, "bendover" stress intensity is also shown. 

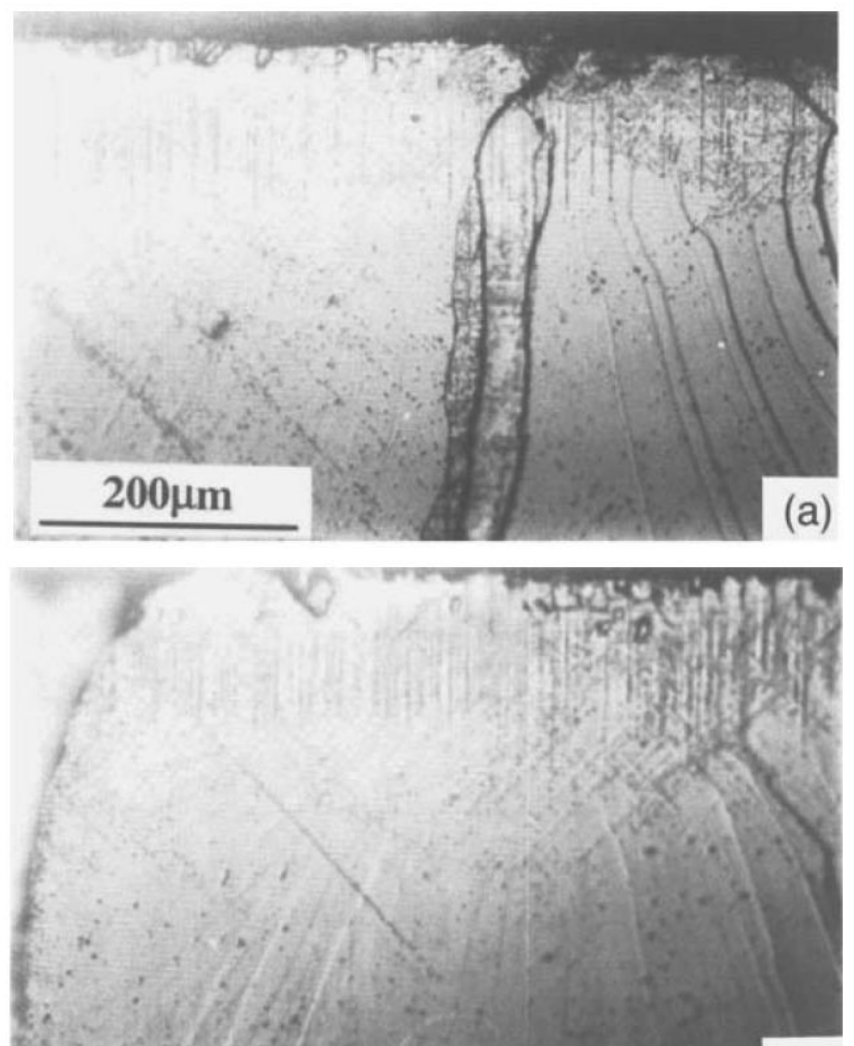

(b)
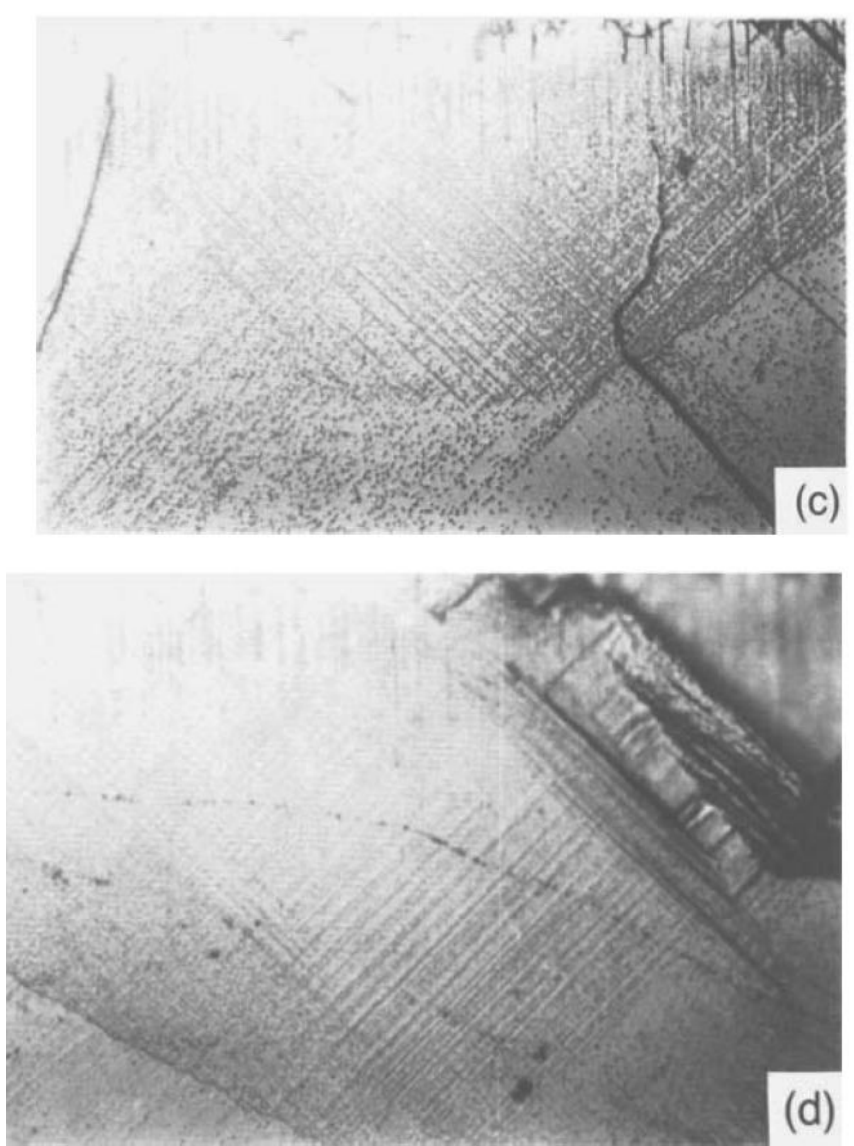

8. Etched fracture surfaces of specimens deformed as in figure $6 \mathrm{a}$ but at (a) $113^{\circ} \mathrm{C}$, (b) $122^{\circ} \mathrm{C},(\mathrm{c}), 149^{\circ} \mathrm{C}$, (d) $181^{\circ} \mathrm{C}$. Substantial stable crack growth is found only above $122^{\circ} \mathrm{C}$; above this temperature its extent increases as the temperature increases. 


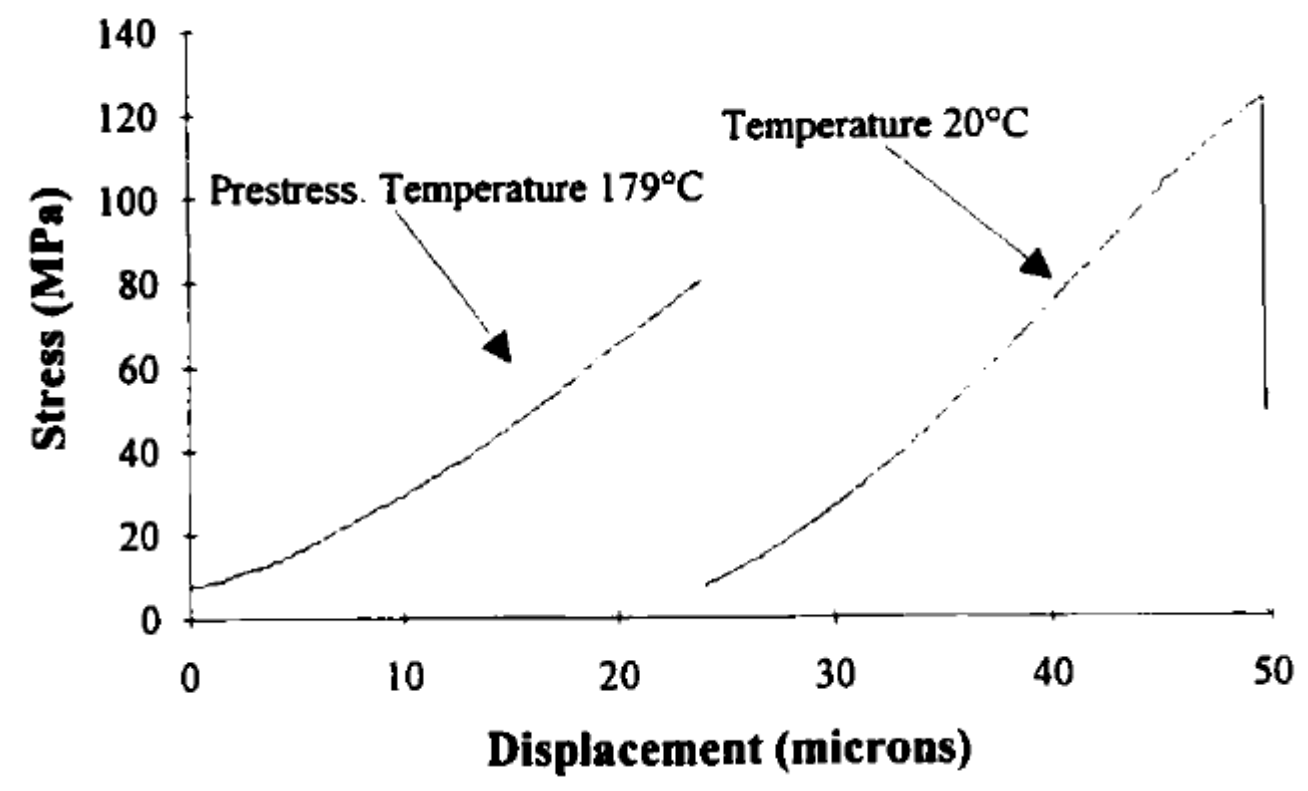

9. Typical stress-displacement curves for the warm-prestressing experiments, showing the prestress and the subsequent room temperature fracture test.

Prestressing increases the room temperature fracture stress. 

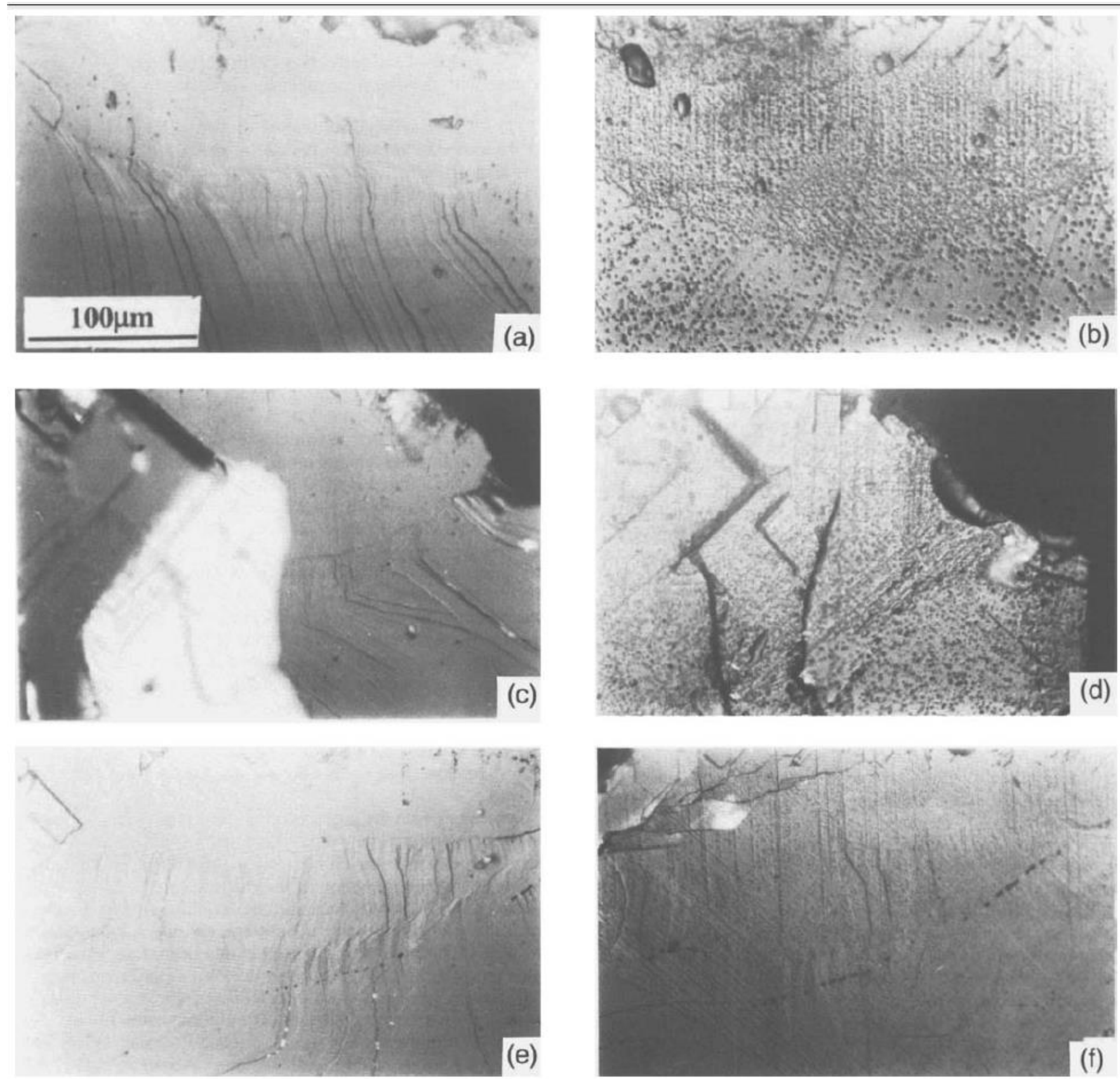

10. Typical unetched $(\mathrm{a}, \mathrm{c}, \mathrm{e})$ and etched $(\mathrm{b}, \mathrm{d}, \mathrm{f})$ fracture surfaces of prestressed specimens after room temperature fracture:

(a,b) prestress $55 \mathrm{MPa}$ at $179^{\circ} \mathrm{C}$;

(c,d) prestress $90 \mathrm{MPa}$ at $179^{\circ} \mathrm{C}$;

$(\mathrm{e}, \mathrm{f})$ prestress $90 \mathrm{MPa}$ at $199^{\circ} \mathrm{C}$.

On the unetched fracture surfaces, the three successive crack fronts can be seen, corresponding to the original pre-crack $(85 \mu \mathrm{m})$, crack after prestressing, and final crack front at the onset of fast fracture. 


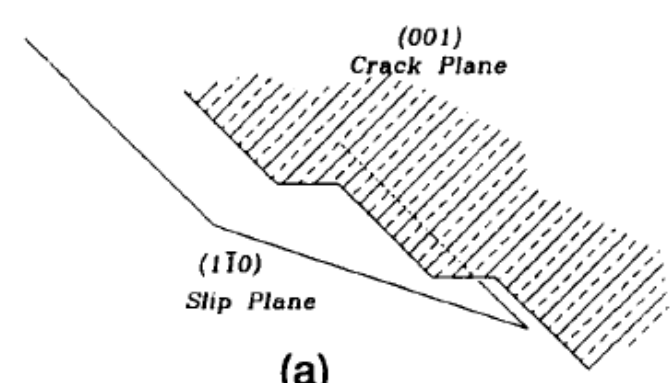

(a)

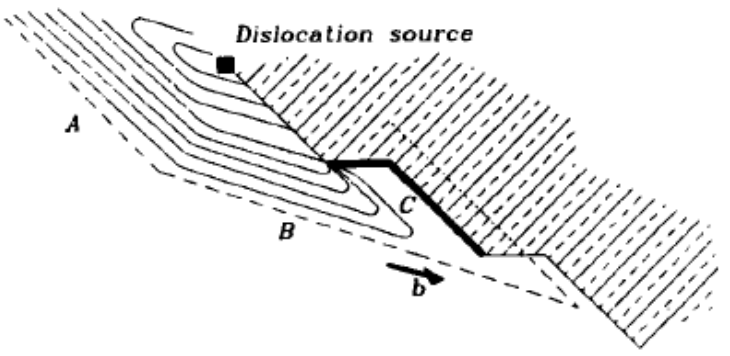

(c)

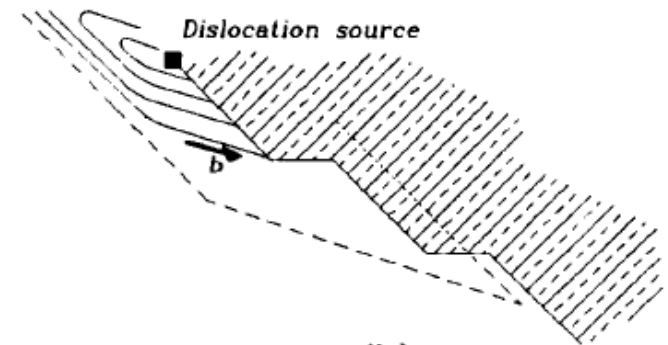

(b)

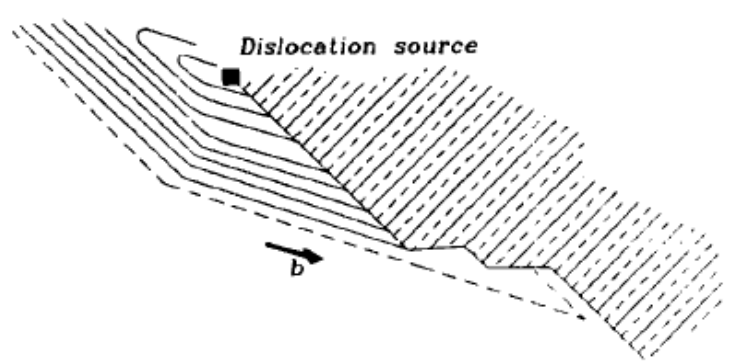

(d)

11. Model for stable crack growth:

(a) Geometry of crack plane and slip plane near steps in the crack tip.

(b) A dislocation source on or near to the crack tip emits shielding dislocations.

(c) The dislocations that have advanced beyond the edge of the crack step (labelled $C$ ) are antishielding with respect to the crack tip beyond the step (shown bold).

(d) The antishielding dislocations raise the local stress intensity at the crack step to above $\mathrm{K}_{1 \mathrm{c}}$ : the crack step advances, attracting and absorbing the antishielding dislocations. $\mathrm{K}$ at the crack tip falls below $\mathrm{K}_{1 \mathrm{c}}$. The process can then restart. 


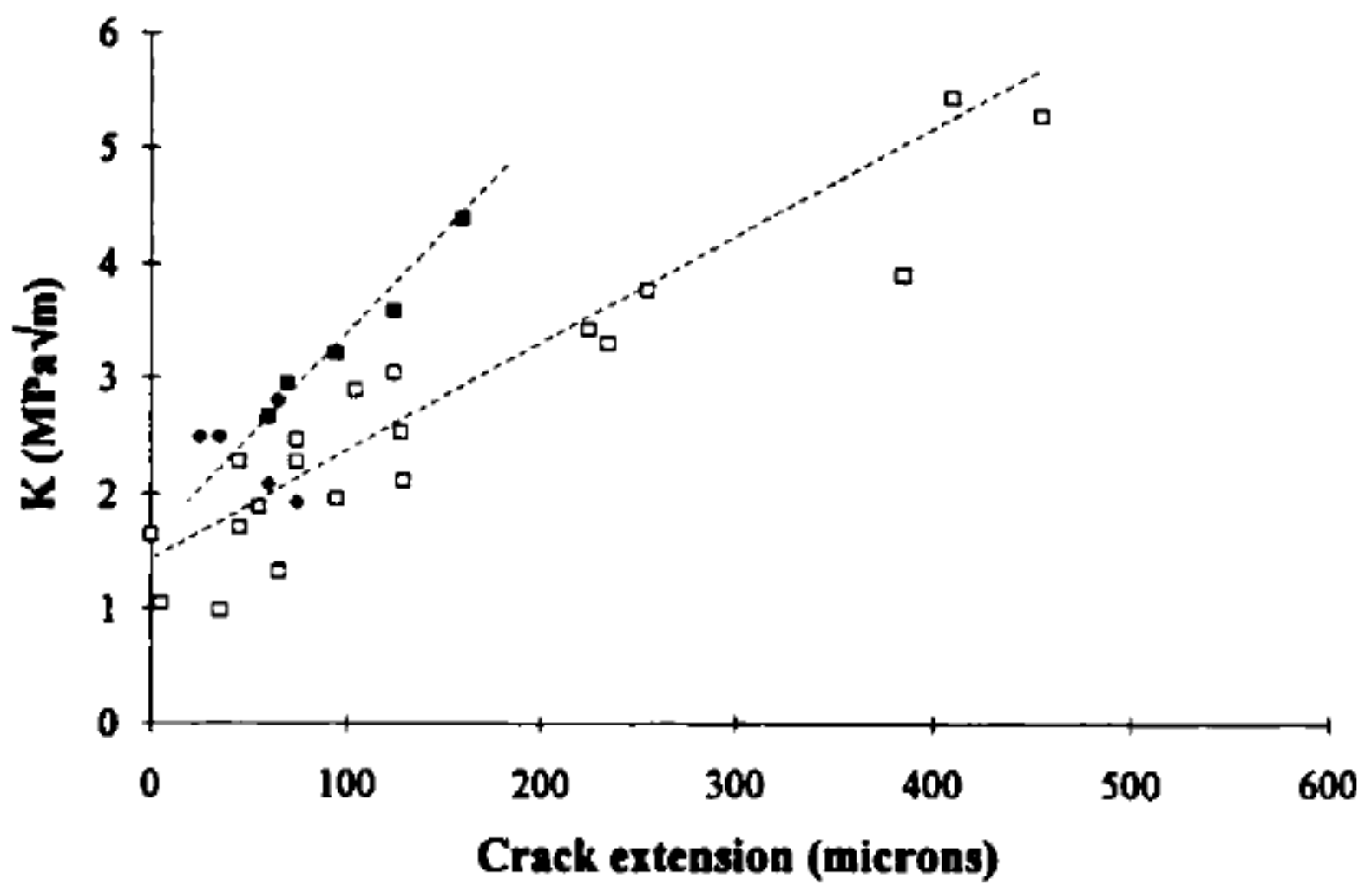

12. Stress intensity at fracture $v s$ crack length at fracture for all tests. The data for all "simple" fracture tests lie in a well defined band; those from warm prestressing experiments show the influence of additional crack shielding. 
Table I

Specimens with $55 \mu \mathrm{m}$ precrack, tested at $5.9 \times 10^{-6} \mathrm{sec}^{-1}$

\begin{tabular}{c|cccc|cccc}
\hline \multirow{2}{*}{$\begin{array}{c}\text { Temp. } \\
\left({ }^{\circ} \mathrm{C}\right)\end{array}$} & $\begin{array}{c}\text { Load } \\
(\mathrm{N})\end{array}$ & $\begin{array}{c}\text { Stress } \\
(\mathrm{MPa})\end{array}$ & $\begin{array}{c}\text { Crack } \\
\text { Size }(\mu \mathrm{m})\end{array}$ & $\begin{array}{c}\mathrm{K} \\
\left(\mathrm{MPa} V_{\mathrm{m}}\right)\end{array}$ & $\begin{array}{c}\text { Load } \\
(\mathrm{N})\end{array}$ & $\begin{array}{c}\text { Stress } \\
(\mathrm{MPa})\end{array}$ & $\begin{array}{c}\text { Crack } \\
\text { Size }(\mu \mathrm{m})\end{array}$ & $\begin{array}{c}\mathrm{K}_{\mathrm{F}} \\
\left(\mathrm{MPa} \sqrt{\mathrm{m}}_{\mathrm{m}}\right)\end{array}$ \\
\hline 20 & 31 & 109 & 55 & 1.52 & 33 & 122 & 280 & 4.0 \\
72 & 32 & 112 & 55 & 1.57 & 33.5 & 115 & 315 & 4.1 \\
146 & 23 & 81 & 55 & 1.13 & 32 & 112 & 650 & 11.2 \\
\hline
\end{tabular}


Table II

Warm Prestressing - variation with prestress at fixed temperature $\left(179^{\circ} \mathrm{C}\right)$.

\begin{tabular}{|c|c|c|c|c|c|}
\hline \multicolumn{3}{|c|}{ Prestressing } & \multicolumn{3}{|c|}{ Room Temperature } \\
\hline $\begin{array}{l}\text { Prestress } \\
(\mathrm{MPa})\end{array}$ & $\begin{array}{l}\text { Crack } \\
\text { length } \\
(\mu \mathrm{m})\end{array}$ & $\frac{\mathrm{K}}{\left(\mathrm{MPa} \bigvee_{\mathrm{m}}\right)}$ & $\begin{array}{c}\text { Fracture } \\
\text { Stress } \\
(\mathrm{MPa})\end{array}$ & $\begin{array}{c}\text { Crack } \\
\text { length }(\mu \mathrm{m})\end{array}$ & $\begin{array}{c}\mathrm{K}_{\mathrm{F}} \\
\left(\mathrm{MPa}_{\mathrm{m}}\right)\end{array}$ \\
\hline- & $(85)$ & & 88 & 140 & 1.92 \\
\hline 50 & 110 & 0.97 & 96 & 150 & 2.16 \\
\hline 55 & 125 & 1.13 & 86 & 160 & 2.01 \\
\hline 65 & 110 & 1.26 & 118 & 150 & 2.66 \\
\hline 80 & 110 & 1.54 & 123 & 120 & 2.48 \\
\hline 90 & 130 & 1.89 & 129 & 180 & 3.20 \\
\hline 92 & 130 & 1.93 & 122 & 145 & 2.70 \\
\hline 104 & 95 & 1.87 & 129 & 110 & 2.49 \\
\hline
\end{tabular}

[The broken line between Prestress values of 55 and $65 \mathrm{MPa}$ indicates the level of "bendover stress" for these conditions - i.e. the stress at which we assume stable crack growth begins.] 
Table III

Warm Prestressing - variation with temperature at fixed prestress.

\begin{tabular}{|c|c|c|c|c|c|c|}
\hline \multirow[b]{2}{*}{$\begin{array}{c}\text { Prestressing } \\
\text { Temperature } \\
\left({ }^{\circ} \mathrm{C}\right)\end{array}$} & \multicolumn{3}{|c|}{ Prestressing } & \multicolumn{3}{|c|}{ Room Temperature } \\
\hline & $\begin{array}{c}\text { Prestress } \\
(\mathrm{MPa})\end{array}$ & $\begin{array}{c}\text { Crack length } \\
\qquad(\mu \mathrm{m})\end{array}$ & $\frac{\mathrm{K}}{\left(\mathrm{MPa} V_{\mathrm{m}}\right)}$ & $\begin{array}{l}\text { Fracture } \\
\text { Stress } \\
\text { (MPa) }\end{array}$ & $\begin{array}{c}\text { Crack } \\
\text { length }(\mu \mathrm{m})\end{array}$ & $\begin{array}{c}\mathrm{K}_{\mathrm{F}} \\
\left(\mathrm{MPa} V_{\mathrm{m}}\right)\end{array}$ \\
\hline (none) & - & (85) & - & 88 & 140 & 1.92 \\
\hline 161 & 90 & 150 & 2.03 & 123 & 180 & 3.06 \\
\hline 170 & 90 & 115 & 1.78 & 125 & 135 & 2.67 \\
\hline 179 & 90 & 130 & 1.89 & 129 & 180 & 3.21 \\
\hline 190 & 90 & 135 & 1.92 & 137 & 200 & 3.61 \\
\hline 199 & 90 & 150 & 2.03 & 147 & 250 & 4.45 \\
\hline
\end{tabular}

